\title{
Lactobacillus pentosus strain S-PT84 improves steatohepatitis by maintaining gut permeability
}

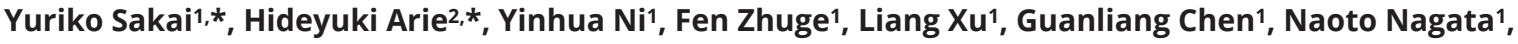 \\ Takuya Suzuki³, Shuichi Kaneko', Tsuguhito Ota1 and Mayumi Nagashimada(D1,2 \\ ${ }^{1}$ Advanced Preventive Medical Sciences Research Center, Kanazawa University, Kanazawa, Japan \\ 2Division of Health Sciences, Graduate School of Medical Science, Kanazawa University, Kanazawa, Japan \\ ${ }^{3}$ Department of Biofunctional Science and Technology, Graduate School of Biosphere Science, Hiroshima University, Higashi-Hiroshima, Japan \\ Correspondence should be addressed to M Nagashimada: nakanaga@staff.kanazawa-u.ac.jp \\ *(Y Sakai and $\mathrm{H}$ Arie contributed equally to this work)
}

\begin{abstract}
Intestinal mucosal barrier dysfunction is closely related to the pathogenesis of nonalcoholic steatohepatitis (NASH). Gut immunity has been recently demonstrated to regulate gut barrier function. The Lactobacillus pentosus strain S-PT84 activates helper T cells and natural killer/natural killer T cells. In this study, we examined the effect of S-PT84 on NASH progression induced by high-cholesterol/high-fat diet (CL), focusing on the immune responses involved in gut barrier function. C57BL/6 mice were fed a normal chow or CL diet with or without $1 \times 10^{10}$ S-PT84 for 22 weeks. S-PT84 administration improved hepatic steatosis by decreasing triglyceride and free fatty acid levels by $34 \%$ and $37 \%$, respectively. Furthermore, S-PT84 inhibited the development of hepatic inflammation and fibrosis, suppressed $\mathrm{F} 4 / 80^{+}$macrophage/Kupffer cell infiltration, and reduced liver hydroxyproline content. Administration of S-PT84 alleviated hyperinsulinemia and enhanced hepatic insulin signalling. Compared with mice fed $\mathrm{CL}$ diet, mice fed CL+S-PT84 had 71\% more CD11c-CD206+ M2 macrophages, resulting in a significantly decreased M1/M2 macrophage ratio in the liver. Moreover, S-PT84 inhibited the $\mathrm{CL}$ diet-mediated increase in intestinal permeability. Additionally, S-PT84 reduced the recruitment of interleukin-17-producing $T$ cells and increased the levels of intestinal tight junction proteins, including zonula occludens-1, occludin, claudin-3, and claudin-7. In conclusion, our findings suggest that S-PT84 attenuates diet-induced insulin resistance and subsequent NASH development by maintaining gut permeability. Thus, S-PT84 represents a feasible approach to prevent the development of NASH.
\end{abstract}

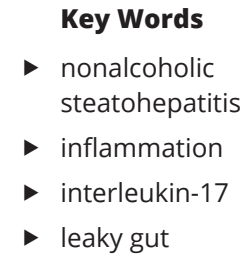

Journal of Endocrinology (2020) 247, 169-181

\section{Introduction}

Nonalcoholic fatty liver disease (NAFLD) is one of the most common liver disorders and is often associated with obesity, diabetes, dyslipidemia, and insulin resistance. Nonalcoholic steatohepatitis (NASH) is a severe form of NAFLD accompanied by hepatic inflammation and progressive fibrosis, often resulting in cirrhosis
(Diehl \& Day 2017). Although novel therapeutic interventions for NASH have been developed in recent years, its global incidence is on the rise (Friedman et al. 2018).

The pathophysiological mechanisms underlying steatosis-NASH progression remain poorly understood. According to the 'multiple parallel-hit' theory of NAFLD, 
oxidative stress, autophagy dysregulation, and aberrant immune and hepatic stellate cell (HSC) activation promote steatosis-NASH progression (Tilg \& Moschen 2010). Lipid overload in the liver enhances lipid peroxidation, leading to reactive oxygen species (ROS) production. Enhanced lipid peroxidation and ROS production activates $\mathrm{T}$ cells, macrophages (i.e. Kupffer cells), and HSCs, exacerbating hepatic insulin resistance, inflammation, and fibrosis (Diehl \& Day 2017). We previously developed a cholesteroland saturated fatty acid-induced lipotoxic NASH model that reflects the pathophysiological characteristics of human NASH. This NASH model exhibited steatohepatitis, cellular ballooning, myofibroblast proliferation, hepatic fibrosis, and hepatic insulin resistance, but not obesity and adipose inflammation (Matsuzawa et al. 2007). CL diet is useful for the study of the NASH model. The number of natural killer $\mathrm{T}$ (NKT) cells in the liver decreases in mice fed a high-fat diet (Li et al. 2005). Additionally, the number of NKT cells in liver biopsies from patients with hepatic steatosis is low (Kremer et al. 2010). The administration of probiotics increases the number of hepatic NKT cells, alleviating inflammation and insulin resistance (Ma et al. 2008). Therefore, innate immune responses are widely believed as crucial regulators of NASH progression.

Altered intestinal barrier function has been implicated in NASH pathogenesis (Tilg et al. 2016). An intact intestinal barrier prevents the permeation of antigens, endotoxins, and other pro-inflammatory substances into the bloodstream. Intestinal barrier dysfunction allows the entry of such molecules into the bloodstream, potentially triggering local and systemic inflammation and resulting in metabolic endotoxemia. Notably, the levels of lipopolysaccharide (LPS), a component of Gram-negative bacteria, and gut permeability are increased in patients with NASH (Miele et al. 2009). Intestinal permeability is regulated by tight junctions (TJs), which consist of several integral proteins, such as zonula occludens (ZO), occludin, junctional adhesion molecule-A (JAM-A), and claudins (Gonzalez-Mariscal et al. 2003). Immune cells in the intestinal lamina propria (LP) play a key role in regulating intestinal permeability (Groschwitz \& Hogan 2009). T cell-derived pro-inflammatory cytokines promote disruption of the TJ structure, increasing intestinal paracellular permeability (Musch et al. 2002, Clayburgh et al. 2005).

Probiotics are widely used to prevent or treat gastrointestinal diseases as they modulate the intestinal microbiota and host immunity. Studies in NASH animal models have shown that various probiotics prevent NASH progression and improve intestinal barrier function
(Paolella et al. 2014). However, the effect of probiotics on intestinal barrier integrity, which is regulated by TJ structure and intestinal immunity, has not been elucidated in detail. Lactobacillus pentosus strain S-PT84 (hereinafter referred to as S-PT84) was first isolated from fermented Japanese Kyoto pickles (shibazuke), which exhibit immunomodulatory properties (Nonaka et al. 2008). We previously reported that live and heat-killed S-PT84 exerted similar immunomodulatory effects in mice (Izumo et al. 2011b). Additionally, the administration of heat-killed S-PT84 enhanced splenic natural killer (NK) and NKT cell activation and protected against viral infection (Izumo et al. 2011c). Heat-killed S-PT84 also promoted IgA production in Peyer's patches, boosting intestinal immunity (Izumo et al. 2011a). The anti-allergic effects of heat-killed S-PT84 by polarising toward a T helper (Th) type 1 immune response have also been demonstrated (Nonaka et al. 2008). Heat-killed S-PT84 has also recently been reported to attenuate metabolic endotoxemia induced by LPS oral administration (Zeng et al. 2019). However, the ability of S-PT84 to ameliorate metabolic syndromes associated with metabolic endotoxemia, such as NASH and diabetes, remains unclear.

The aim of this study was to investigate the effects of heat-killed S-PT84 on the development of lipotoxic NASH induced by a CL diet. In particular, we focused on the effects of S-PT84 on hepatic innate immunity, gut immunity, and intestinal epithelial barrier function.

\section{Materials and methods}

\section{Preparation of heat-killed S-PT84}

S-PT84 was cultured in deMan, Rogosa, and Sharpe broth (Difco Laboratories, Detroit, MI, USA) at $37^{\circ} \mathrm{C}$ for $24 \mathrm{~h}$ and harvested via centrifugation. The bacteria were washed twice with sterile saline, washed again with distilled water, and heat-killed at $95^{\circ} \mathrm{C}$ for $5 \mathrm{~min}$. No colonies formed on agar plates, confirming the non-viability of the heat-killed S-PT84. Heat-killed S-PT84 were freeze-dried and used for the following experiments.

\section{Mice and diets}

Seven-week-old male C57BL/6J mice were purchased from Charles River Laboratories and acclimatised for 1 week. The mice were divided into three groups and fed the following diets for 22 weeks: (1) normal chow (NC) with $10 \%$ calories from fat (CRF-1, Charles River 
Laboratories); (2) high-cholesterol high-fat (CL) diet with $60 \%$ calories from fat, $1.25 \%$ cholesterol, and $0.5 \%$ sodium cholate (Research Diets); and (3) CL diet with $1 \times 10^{10}$ S-PT84 added. Heat-killed S-PT84 was added to $\mathrm{CL}$ diet at $0.564 \%(\mathrm{w} / \mathrm{w})$; hence, $4 \times 10^{9} \mathrm{~S}$-PT84 was included per $1 \mathrm{~g}$ of the diet. Given a $2.5 \mathrm{~g}$ diet/day, mice received $1 \times 10^{10} \mathrm{~S}$-PT84/day. All mice were maintained in a $12 \mathrm{~h}$ light: $12 \mathrm{~h}$ darkness cycle and allowed free access to food and water. All animal procedures were performed in accordance with institutional guidelines and approved by the Animal Care and Use Committee of Kanazawa University.

\section{Histological examination and immunohistochemistry}

Liver sections embedded in paraffin wax were stained with hematoxylin and eosin, Sirius red, and antibodies against F4/80 (Abcam) or $\alpha$-smooth muscle actin (SMA; Santa Cruz Biotechnology), as described previously ( $\mathrm{Ni}$ et al. 2015). For immunohistological staining, livers were stained with F4/80 and $\alpha$-SMA. Positive staining for anti-F4/80 was quantified as the percentage of positive cells per field using AxioVision SE64 imaging software (Rel. 4.9.1; Carl Zeiss Microscopy) as described previously (Ni et al. 2020).

\section{Biochemical analysis}

After overnight fasting, the levels of plasma triglyceride (TG), total cholesterol (TC), non-esterified fatty acid (NEFA), aspartate aminotransferase (AST), alanine aminotransferase (ALT), glucose, and insulin, as well as concentrations of hepatic TG, TC, and, NEFA were quantified, according to the manufacturer's instructions (FUJIFILM Wako Pure Chemical, Osaka, Japan) and as described previously (Ni et al. 2015). Liver thiobarbituric acid reactive substances (TBARS) were extracted and measured according to the instructions provided with the TBARS assay kit (Cayman Chemicals) and as described previously (Ni et al. 2015). Plasma insulin levels were measured using a mouse insulin ELISA kit (Morinaga Institute of Biological Science, Kanagawa, Japan) as described previously (Ni et al. 2015). After 18 or 19 weeks, glucose tolerance tests (GTTs) and pyruvate tolerance tests (PTTs) were conducted after overnight fasting. Blood was collected from the tail vein, and mice were injected intraperitoneally with $2 \mathrm{~g} / \mathrm{kg}$ glucose or $2 \mathrm{~g} / \mathrm{kg}$ pyruvate. Plasma lipopolysaccharide (LPS) binding protein (LBP) levels were measured using a commercially available ELISA kit (Biometec, Greifswald, Germany).

\section{Immunoblot analysis of liver tissues}

Liver tissues were homogenized and sonicated in radioimmunoprecipitation lysis buffer (Millipore) supplemented with cOmplete ethylenediaminetetraacetic acid (EDTA)-free protease inhibitor (Roche Diagnostics) and PhosSTOP phosphatase inhibitor (Roche Diagnostics). Western blotting was performed according to a previously reported method (Matsuzawa et al. 2007). The antibodies used are listed in Supplementary Table 1 (see section on supplementary materials given at the end of this article).

\section{Quantitative real-time polymerase chain reaction (qPCR)}

Total RNA was isolated from frozen liver samples using a High Pure RNA Isolation kit (Roche Diagnostics). Then, cDNA was synthesized using a High-Capacity cDNA RT kit (Applied Biosystems), and qPCR was performed on a CFX384 instrument (Bio-Rad) using SYBR Green Master Mix (Kitade et al. 2012). The primers used for qPCR are listed in Supplementary Table 2. The mRNA levels were normalized to those in NC-fed mice.

\section{Isolation of liver macrophages}

Liver macrophages were isolated as described previously (Ni et al. 2015, Zhuge et al. 2016). The left lobes of the livers were gently lysed and digested for $20 \mathrm{~min}$ at $37^{\circ} \mathrm{C}$ using type IV collagenase (Sigma-Aldrich) and type I deoxyribonuclease in PBS containing 2\% BSA (pH 7.4).

\section{Flow cytometry}

Cells were incubated in $0.5 \mu \mathrm{g} / \mathrm{mL}$ phorbol myristate acetate (Fujifilm Wako), $1 \mu \mathrm{g} / \mathrm{mL}$ ionomycin (Fujifilm Wako), and $1 \mu \mathrm{g} / \mathrm{mL}$ GolgiPlug (BD Biosciences, San Jose, CA) in PBS containing $2 \%$ fetal bovine serum (FBS) for $1 \mathrm{~h}$ at $37^{\circ} \mathrm{C}$. The cells were washed with PBS containing $2 \%$ FBS and fixed with $4 \%$ paraformaldehyde in PBS ( $\mathrm{pH} 7.4$; BD Biosciences) for $20 \mathrm{~min}$. Next, the cells were permeabilized in BD Perm/Wash buffer (10x; BD Biosciences) and incubated with fluorochromeconjugated antibodies (Lee et al. 2015). Macrophages/ Kupffer cells were incubated with Fc Block (BD Biosciences) and then with fluorochrome-conjugated antibodies (Supplementary Table 3). The cells were analyzed using a FACSAria II flow cytometer (BD Biosciences) as described previously (Ni et al. 2015, Zhuge et al. 2016). Lamina propria (LP) cells were identified as 
CD45+NK1.1-CD3+CD4+IL-17+ (Supplementary Fig. 1A and B). Data analysis and compensation were performed using FlowJo software (ver. 8.8.7; Tree Star, Ashland, OR, USA).

\section{Intestinal permeability assay}

Mice were fasted for $6 \mathrm{~h}$ and administered $1 \mathrm{mg} / \mathrm{kg}$ 5,(6)-carboxyfluorescein (CF; Sigma-Aldrich) via oral gavage. The plasma CF level was determined before loading and at 2 and $4 \mathrm{~h}$ after loading. The plasma was diluted in water and analyzed for CF concentration using a TriStar LB 941 fluorescence spectrophotometer (Berthold Technologies, Bad Wildbad, Germany). Standard curves were generated based on CF diluted in water.

\section{Isolation of intestinal epithelial cells and immunoblot analysis}

Proximal intestinal tissues (3 $\mathrm{cm}$ long) were washed with saline and cut into five or six small segments. The intestinal segments were transferred into $3 \mathrm{~mL}$ of isolation buffer $\left(\mathrm{Ca}^{2+-}\right.$ and $\mathrm{Mg}^{2+}$-free Hanks' balanced salt solution supplemented with $0.1 \mathrm{mmol} / \mathrm{L}$ dithiothreitol (DTT), 5 $\mathrm{mmol} / \mathrm{L}$ EDTA, and protease and phosphatase inhibitors) and incubated for $1 \mathrm{~h}$ with gentle agitation. The tissue was then vigorously shaken to release epithelial cells. The supernatants were centrifuged at $5,000 \times \mathrm{g}$ for $2 \mathrm{~min}$ to sediment epithelial cells. The pellets were homogenized in lysis buffer containing $1 \%(\mathrm{w} / \mathrm{v})$ sodium dodecyl sulfate (SDS), 1\% (v/v) TritonX-100, and 1\% (w/v) sodium deoxycholate in $30 \mathrm{mmol} / \mathrm{L}$ Tris with protease and phosphatase inhibitors ( $\mathrm{pH}$ 7.4) using an ultrasonic cell homogenizer (VP-050; Taitec, Koshigaya, Japan). Protein concentrations were measured using the bicinchoninic acid method (Thermo Fisher Scientific). Tissue extracts were mixed with a $0.5 \times$ volume of Laemmli sample buffer (3x concentrated) containing 6\% (w/v) SDS, 30\% (v/v) glycerol, $15 \%$ (v/v) $\beta$-mercaptoethanol, and $0.02 \%(\mathrm{w} / \mathrm{v})$ bromophenol blue in $188 \mathrm{mmol} / \mathrm{L}$ Tris (pH 6.8). The samples were next heated to $100^{\circ} \mathrm{C}$ for $5 \mathrm{~min}$. Proteins $(20 \mu \mathrm{g})$ were separated using SDS-PAGE and transferred to polyvinylidene fluoride membranes. The membranes were blotted for ZO-1, ZO-2, JAM-A, occludin, claudin-3, claudin-4, and claudin-7 using specific antibodies in combination with a horseradish peroxidase-conjugated anti-rabbit immunoglobulin (Ig) G antibody. The antibodies used are listed in Supplementary Table 4. Quantification was performed via densitometric analysis of specific immunoblot bands using Image $\mathrm{J}$ software (version $1.51 ; \mathrm{NIH}$ ).

\section{Immunofluorescence of intestinal TJ proteins}

Mouse small intestine and colon tissue were embedded in optimum cutting temperature compound (Sakura Finetek, Tokyo, Japan), and frozen sections ( $8 \mu \mathrm{m}$ thickness) were mounted on glass slides. The colon sections were fixed in $4 \%(\mathrm{w} / \mathrm{v})$ paraformaldehyde for $10 \mathrm{~min}$ and washed three times with PBS. The sections were blocked in 4\% skim milk for $30 \mathrm{~min}$ and then incubated with rabbit polyclonal anti-ZO-1, -claudin-3, and -claudin-7 antibodies at $4^{\circ} \mathrm{C}$ for $16 \mathrm{~h}$, followed by a goat AlexaFluor 488-conjugated anti-rabbit secondary IgG for $1 \mathrm{~h}$. The specimens were preserved in mounting medium, and fluorescence was visualized using a confocal microscope (LSM700; Carl Zeiss Microscopy). The antibodies used are listed in Supplementary Table 4 .

\section{Isolation of colonic LP cells}

Colonic LP cells, including lymphocytes, macrophages, dendritic cells, and other immune cells, were isolated as described previously (Denning et al. 2007). Mesenteric fat was carefully removed from the colon. The colon was cut open longitudinally, washed, and cut into $0.5-\mathrm{cm}$ pieces. The colon tissue pieces were incubated in PBS containing dithiothreitol (DTT) for $10 \mathrm{~min}$ at $37^{\circ} \mathrm{C}$. The supernatant was discarded, and the tissue was incubated in PBS containing EDTA for $20 \mathrm{~min}$ at $37^{\circ} \mathrm{C}$ and vortexed for $30 \mathrm{~s}$ to remove epithelial cells. Following incubation, the supernatant was discarded, and the remaining tissue was minced and incubated in RPMI medium containing $5 \mathrm{mg} / \mathrm{mg}$ collagenase (Fujifilm Wako), $1 \mathrm{mg} / \mathrm{mL}$ dispase, $2 \mathrm{mg} / \mathrm{mL}$ DNase, and 2\% BSA (pH 7.4). After a $15 \mathrm{~min}$ incubation at $37^{\circ} \mathrm{C}$ with agitation, the cells were collected, passed through a $50 \mu \mathrm{m}$ cell strainer, and centrifuged. The pellets were resuspended in 40\% Percoll, transferred into a new tube, underlaid with $80 \%$ Percoll, and centrifuged at $1000 \mathrm{~g}$ for $20 \mathrm{~min}$ at room temperature. After centrifugation, the white interphase was transferred into a new tube and washed in PBS containing 2\% fetal bovine serum.

\section{Statistical analysis}

Data are presented as the means \pm S.E.M. Differences between the two groups were assessed using two-tailed Student's $t$-tests. Differences among more than two groups were assessed using ANOVA. If one-way ANOVA yielded a significant result, pair-wise differences between groups were analyzed using the Tukey post hoc test. Correlation analysis was performed using the Pearson test. 
All calculations were performed using SPSS software (ver. 23.0, IBM). A value of $P<0.05$ was considered indicative of significance.

\section{Results}

\section{S-PT84 attenuates diet-induced hepatic steatosis, glucose intolerance, and insulin resistance}

We assessed the effects of CL diet containing $1 \times 10^{8}$ or $1 \times 10^{10}$ S-PT84/day and found that S-PT84-containing diet for 15 weeks ameliorated liver pathology and decreased plasma ALT levels in diet-induced NASH mice in a dose-dependent manner (Supplementary Fig. 2A and $B)$; these effects were more prominent in mice treated with $1 \times 10^{10}$ S-PT84/day. Therefore, we performed further investigations using this group (hereafter referred to as CL+S-PT84). Twenty-two weeks of S-PT84 feeding did not affect the body weight of CL-fed mice (Fig. 1A and Table 1). Liver and epididymal white adipose tissue (eWAT) weights were lower in CL+S-PT84 mice than in CL mice (Fig. 1B and Table 1). Additionally, eWAT weights were lower in
A

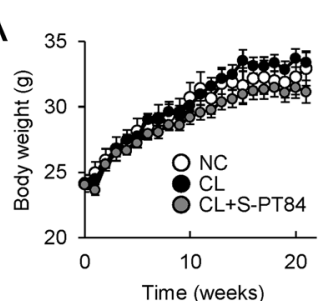

B

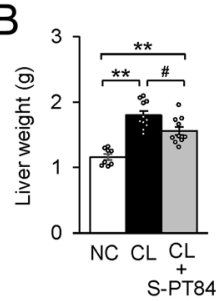

$\mathrm{C}_{\mathrm{NC}}$
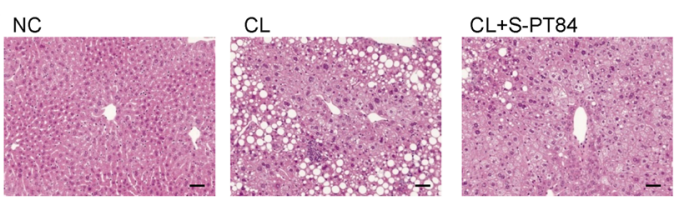

D

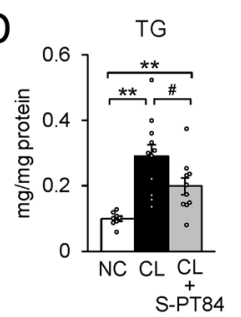

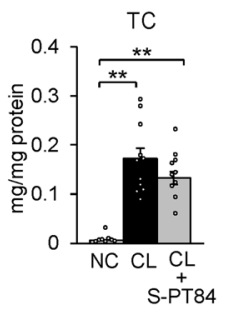
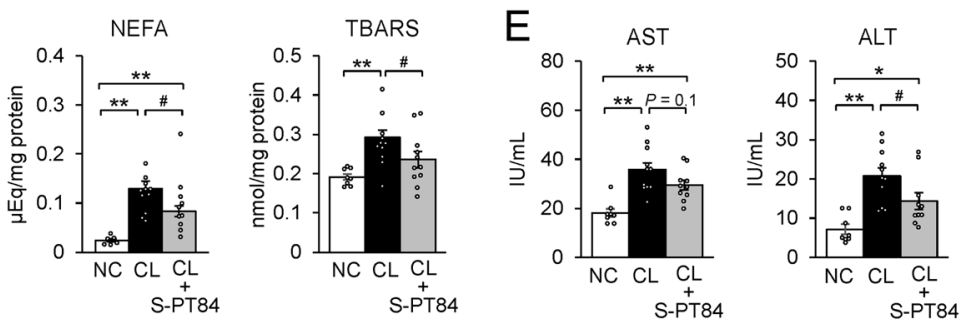

$\mathrm{F}$
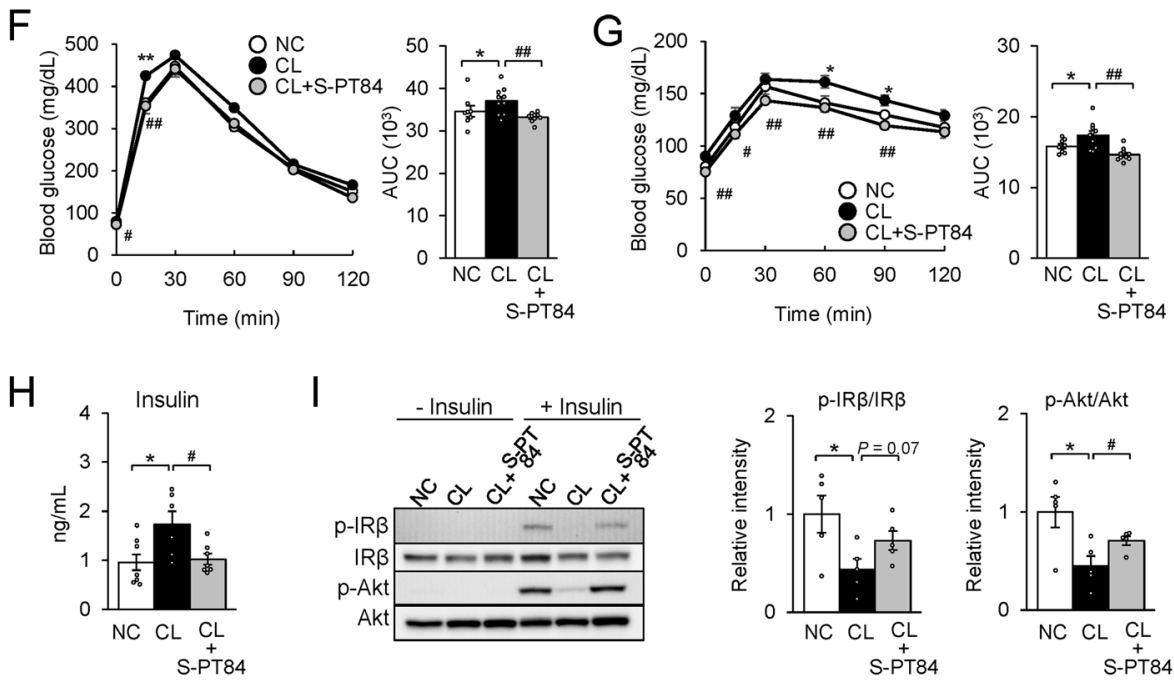

Figure 1

S-PT84 reduces hepatic lipid accumulation and ameliorates diet-induced glucose intolerance. (A) Weight gain in mice fed normal chow (NC) or highcholesterol high-fat (CL) diet with or without S-PT84 $(n=8-11)$. (B) Liver weight $(n=8-11)$. (C) Representative hematoxylin-eosin (H\&E) stained liver sections. Scale bars $=100 \mu \mathrm{m}$. (D) Hepatic plasma triglycerides (TGs), total cholesterol (TC), non-esterified fatty acids (NEFAs), and thiobarbituric acid reactive substances (TBARS) content $(n=8-11)$. (E) Plasma aspartate aminotransferase (AST) and alanine aminotransferase (ALT) levels $(n=8-11)$. (F) Glucose tolerance test $(n=8-10)$. (G) Pyruvate tolerance test $(n=8-10)$. (H) Plasma insulin levels $(n=6-7)$. (I) Immunoblots showing the levels of phosphorylated insulin receptor- $\beta$ subunit ( $p-I R \beta)$ and Akt (p-Akt) in the liver $(n=5)$. Data are presented as mean \pm S.E.M. * $P<0.05$; $* * P<0.01$ vs NC; $\# P<0.05$, \#\#P<0.01 vs CL. NC, normal chow group; CL, high-cholesterol high-fat diet group; CL+S-PT84, CL with S-PT84 group. 
CL+S-PT84 mice than in NC mice. Food intake, plasma TC, and NEFA were unaffected by S-PT84 treatment in CL-fed mice (Table 1). Although the CL diet decreased plasma TG levels, which increased by S-PT84 treatment (Table 1). Histological analyses of CL mouse livers revealed profound lipid accumulation and hepatic ballooning, which were decreased by S-PT84 (Fig. 1C). Further, S-PT84 alleviated hepatic steatosis by decreasing hepatic TG and NEFA levels (Fig. 1D). In addition, the levels of the lipid peroxidation indicator TBARS were increased in the livers of CL-fed mice but were decreased by S-PT84 (Fig. 1D). Moreover, S-PT84 inhibited the increase in plasma ALT and AST levels (Fig. 1E).

GTTs and PTTs indicated that CL+S-PT84 mice exhibited improved glucose tolerance and hepatic insulin resistance compared with CL-fed mice (Fig. 1F and $\mathrm{G})$. We also observed hyperinsulinemia in NASH mice; nevertheless, S-PT84 decreased plasma insulin levels (Fig. 1H). Furthermore, compared with CL-fed mice, insulin-stimulated phosphorylation of the insulin receptor- $\beta$ subunit ( $\mathrm{p}$-IR $\beta$ ) and Akt (p-Akt) was increased in the liver and eWAT of CL+S-PT84 mice (Fig. 1I and Supplementary Fig. 3). These results suggest that S-PT84 protected mice against diet-induced insulin resistance and glucose intolerance.

\section{S-PT84 alleviates hepatic inflammation and fibrosis in NASH mice}

S-PT84 decreased the number of $\mathrm{F} 4 / 80^{+}$macrophages/ Kupffer cells in the livers of CL mice (Fig. 2A and B).

Table 1 Effects of S-PT84 on metabolic parameters after 22 weeks of treatment.

\begin{tabular}{|c|c|c|c|}
\hline & $\mathbf{N C}$ & CL & CL+S-PT84 \\
\hline Body weight (g) & $32.9 \pm 1.3$ & $33.4 \pm 0.7$ & $31.5 \pm 0.9$ \\
\hline $\begin{array}{l}\text { Food intake } \\
\text { (kcal/day) }\end{array}$ & $11.3 \pm 0.2$ & $12.4 \pm 0.9$ & $13.4 \pm 0.5$ \\
\hline $\begin{array}{l}\text { Epididymal fat } \\
\text { weight (g) }\end{array}$ & $0.82 \pm 0.11$ & $1.09 \pm 0.10$ & $0.56 \pm 0.04 a, c$ \\
\hline $\begin{array}{l}\text { Plasma TG } \\
\text { (mg/dL) }\end{array}$ & $91.5 \pm 6.0$ & $53.5 \pm 2.6^{b}$ & $68.1 \pm 4.1 b, c$ \\
\hline $\begin{array}{l}\text { Plasma TC } \\
\text { (mg/dL) }\end{array}$ & $85.3 \pm 4.5$ & $130.5 \pm 4.7^{b}$ & $137.0 \pm 7.2^{b}$ \\
\hline $\begin{array}{l}\text { Plasma NEFA } \\
(\mathrm{mEq} / \mathrm{L})\end{array}$ & $0.39 \pm 0.04$ & $0.44 \pm 0.04$ & $0.37 \pm 0.04$ \\
\hline
\end{tabular}

Data were obtained from 28-week-old fasted mice. Data are presented as mean \pm S.E.M. $(n=8-11)$.

a $P<0.05, \mathrm{~b} P<0.01$ vs NC, $c P<0.01$ vs $C L$.

$\mathrm{CL}$, high-cholesterol high-fat diet group; $\mathrm{CL}+\mathrm{S}-\mathrm{PT} 84, \mathrm{CL}$ with S-PT84 group; NC, normal chow group; NEFA, non-esterified fatty acids; TC, total cholesterol; TG, triglycerides.

(C) 2020 Society for Endocrinology Published by Bioscientifica Ltd. Printed in Great Britain
In addition, S-PT84 decreased the expression of C-X-C motif chemokine 10 ( Cxcl10), C-C motif chemokine ligand 2 (Ccl2), and pro-inflammatory cytokines including

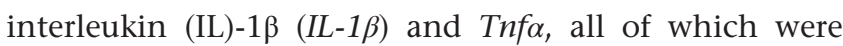
upregulated by CL diet (Fig. 2B). S-PT84-treated mice exhibited reduced oxidative stress and expression of proinflammatory cytokines (Figs 1D and 2B). Consistently, S-PT84 attenuated inflammatory signaling events, such as phosphorylation of p38 mitogen-activated protein kinase

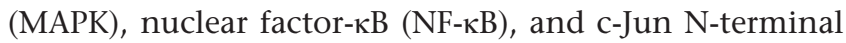
kinase (JNK) (Fig. 2C).

Histological analysis using Sirius red staining revealed that the CL diet alone induced fibrosis, as reported previously (Matsuzawa et al. 2007); S-PT84 prevented the development of hepatic fibrosis in CL-fed mice (Fig. 2D). In addition, the levels of hydroxyproline, a biochemical marker of hepatic collagen content, were significantly higher in CL mice than in NC mice. Importantly, S-PT84 significantly decreased hydroxyproline levels (Fig. 2E). S-PT84 also decreased the number of SMA-positive HSCs in mice fed CL diet (Fig. 2F). These observations were confirmed via immunoblotting and qPCR (Fig. 2G). Additionally, S-PT84 inhibited the CL-mediated increase in Col1a1 and Pai1 expression (Fig. 2H). These findings suggest that S-PT84 alleviated the accumulation of collagen by inhibiting the activation of HSCs in the liver, thereby attenuating hepatic fibrosis.

\section{S-PT84 polarises liver macrophages towards an M2-like phenotype}

Tissue macrophages are phenotypically heterogeneous and usually characterized based on their polarisation/ activation state as pro-inflammatory M1-like or antiinflammatory M2-like macrophages (Mantovani et al. 2004). Here, we quantified hepatic macrophage subsets using flow cytometry. CL-fed mice had higher total numbers of hepatic macrophages $\left(\mathrm{CD} 45^{+} \mathrm{CD} 11 \mathrm{~b}^{+} \mathrm{F} 4 / 80^{+}\right)$ than NC mice (Fig. 3A and B). However, the total hepatic macrophage number was unaffected by S-PT84 treatment (Fig. 3A and B). The number of CD11c ${ }^{+}$CD206 ${ }^{-}$ (M1-like) macrophages did not differ significantly between CL+S-PT84 and CL mice. By contrast, the number of CD11c-CD206+ (M2-like) macrophages was significantly higher in CL+S-PT84 mice than in CL mice (Fig. 3A and B). The flow cytometry results were confirmed by the increased mRNA levels of the M2-like macrophage marker Cd206 (Fig. 3C). Expression of CCR2 and Ly6C in infiltrating monocytes and monocyte-derived 
A
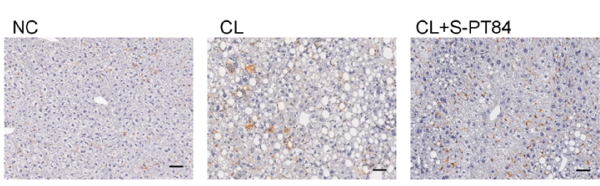

B
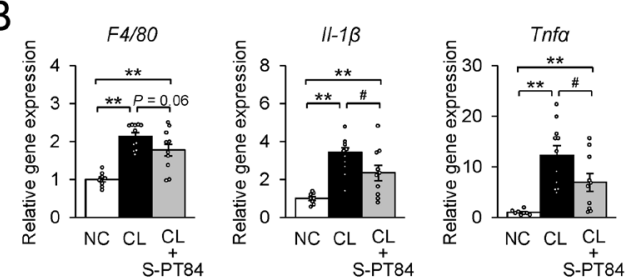
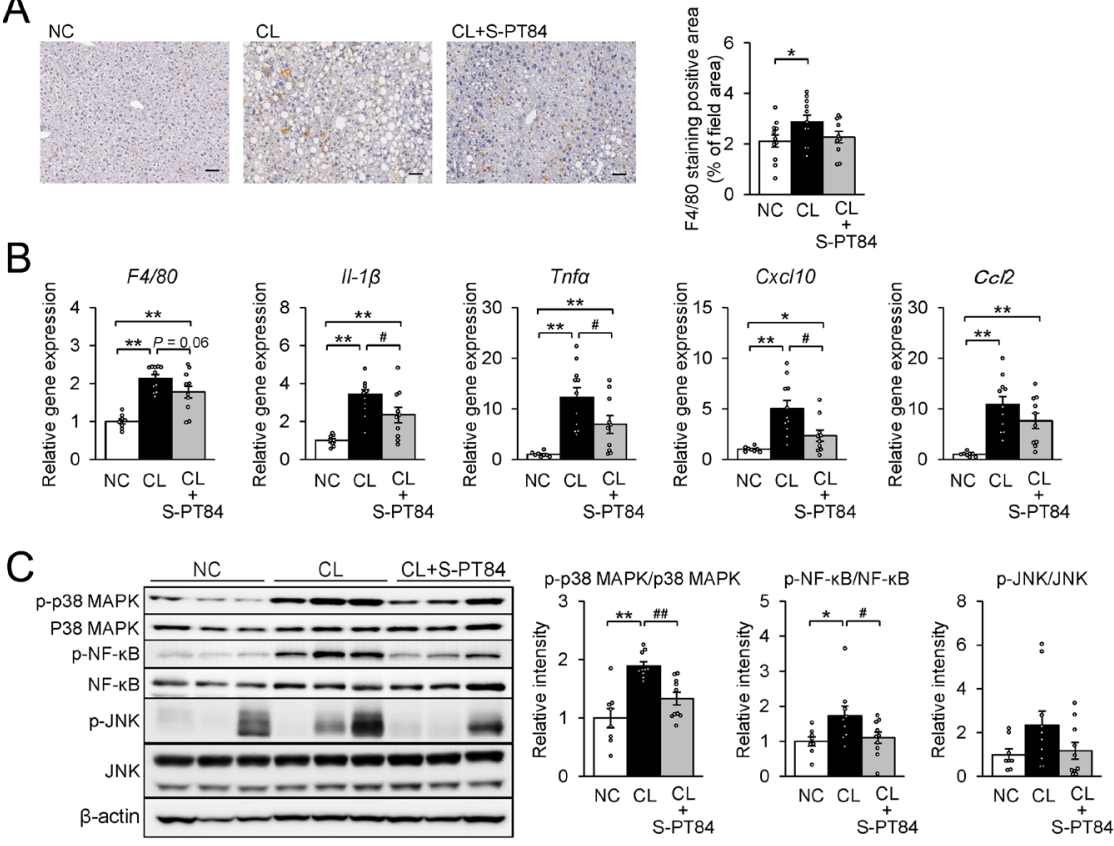

$D_{\mathrm{NC}}$
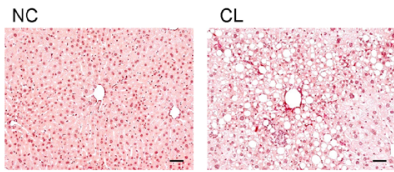

$\mathrm{F}_{\text {NO }}$
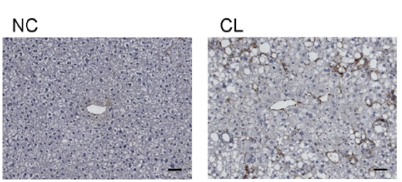

CL+S-PT84
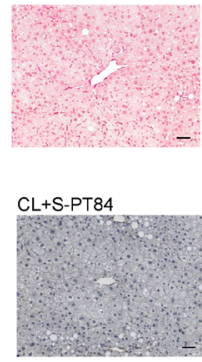

E

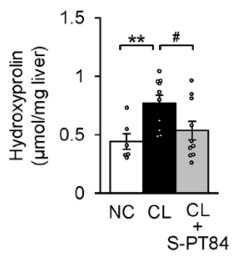

G

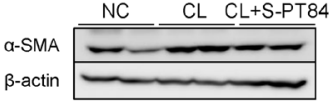

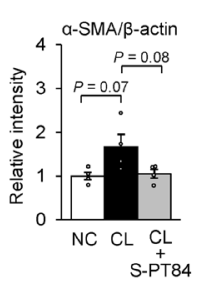

$\mathrm{H}$

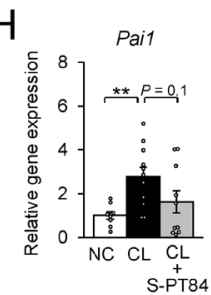

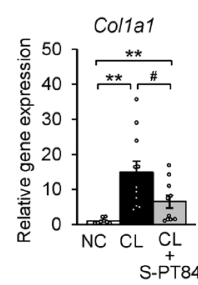

\section{Figure 2}

S-PT84 attenuates inflammatory signaling and reduces hepatic fibrosis. (A) F4/80 immunostaining and quantification of the F4/80 positive area in mouse livers $(n=10-11)$. Scale bars $=100 \mu \mathrm{m}$. (B) Gene expression of F4/80, interleukin-1 $\beta(I I-1 \beta)$, Tnf $\alpha$, C-X-C motif chemokine $10(\mathrm{C} x \mathrm{C} / 10)$, and $\mathrm{C}-\mathrm{C}$ motif chemokine ligand 2 (CCl2) in mouse livers $(n=8-11)$. (C) Immunoblots and quantitation of p-p38 mitogen-activated protein kinase (MAPK), p-nuclear factor (NF)-kB p65, and $\mathrm{p}$-c-Jun $\mathrm{N}$-terminal kinase (JNK) levels in the liver $(n=8-10)$. (D) Sirius red stained liver sections from mice. Scale bars $=100 \mu \mathrm{m}$. $(E)$ Hepatic hydroxyproline content $(n=6-10)$. (F) $\alpha$-Smooth muscle actin (SMA) immunostaining in liver sections. Scale bars $=100 \mu \mathrm{m}$. (G) Immunoblot and quantification of liver $\alpha$-SMA $(n=4)$. (H) Liver gene expression of Pai1 and Col1a1 $(n=8-11)$. Data are presented as mean \pm S.E.M. $* P<0.05 ; * * P<0.01$ vs NC; $\# P<0.05$, $\# P<0.01$ vs $\mathrm{CL}$. NC, normal chow group; $\mathrm{CL}$, high-cholesterol high-fat diet group; CL+S-PT84, CL with S-PT84 group. macrophages plays a vital role in the development of NASH (Kazankov et al. 2019); S-PT84 treatment decreased expression levels of these markers (Fig. 3C). LPS leakage can lead to liver steatosis and inflammation by inducing inflammatory cascades and macrophage/Kupffer cell activation. Toll-like receptor 4 (TLR4) and CD14 are LPS receptors that activate macrophages (Tilg et al. 2016). The M1 to M2 (M1/M2) ratio was positively correlated with Tlr4 and Cd14 mRNA levels (Fig. 3D). These results suggest that S-PT84 shifts liver macrophage polarisation toward an M2-like phenotype.

\section{S-PT84 decreases CD8 ${ }^{+} \mathrm{T}$ cell abundance and increases $\mathrm{CD4}^{+} \mathrm{T}$ cell accumulation in the NASH liver}

Next, we investigated the effects of S-PT84 on T cell recruitment in the liver. CL diet increased the number of $\mathrm{CD}^{+}$and $\mathrm{CD} 8+\mathrm{T}$ cells in the liver, whereas it significantly decreased the number of CD4 ${ }^{+}$T cells. S-PT84 inhibited the accumulation of cytotoxic $\mathrm{T}$ cells and increased the infiltration of $\mathrm{CD}^{+} \mathrm{T}$ cells (Supplementary Fig. 4A and B).

Additionally, we examined the effects of S-PT84 on NKT cells and regulatory $\mathrm{T}$ cells (Tregs) in the liver. 
A

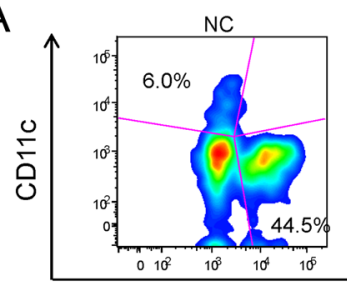

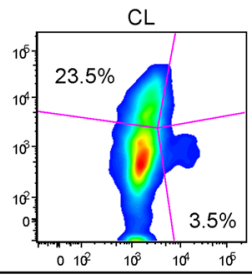

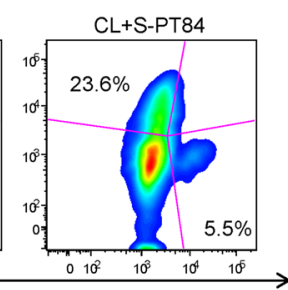

CD206

B

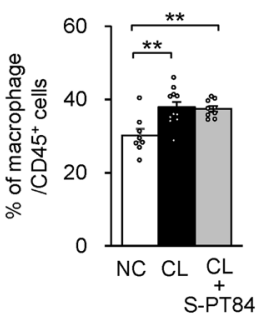

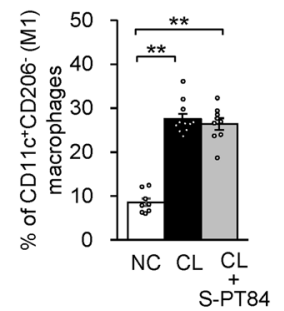
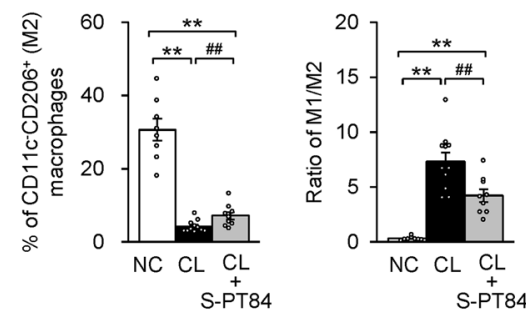

c
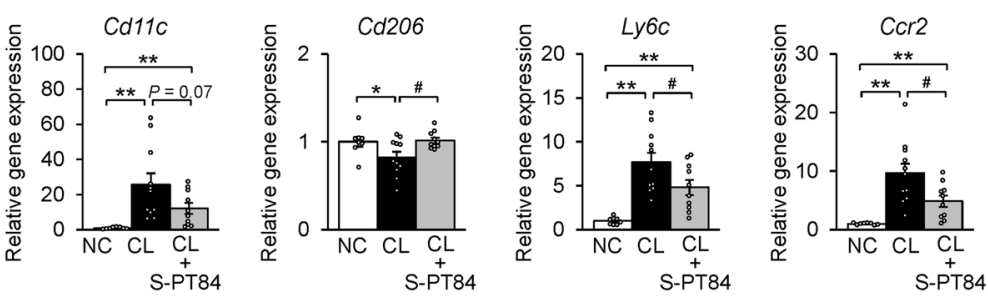

D
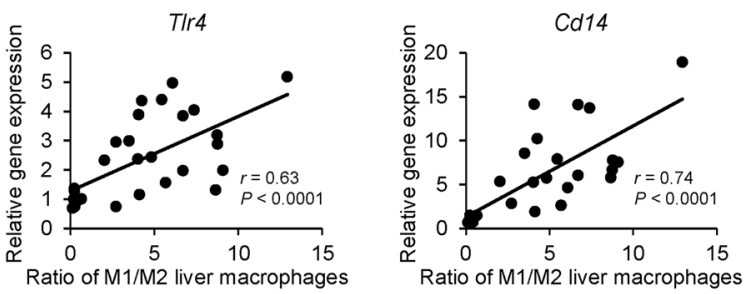

Compared with NC mice, NASH mice had fewer $\mathrm{CD}^{+}{ }^{+} \mathrm{CD} 1 \mathrm{~d}^{+}$NKT cells and more $\mathrm{CD} 4{ }^{+} \mathrm{CD} 25^{+}{ }^{+}$oxP3 ${ }^{+}$ Tregs. However, S-PT84 did not affect the abundance of NKT cells and Tregs in the liver of mice fed CL diet (Supplementary Fig. 4A and B).

\section{S-PT84 maintains intestinal epithelial barrier permeability}

A high-fat diet has been shown to increase gut permeability and promote metabolic endotoxemia, which can trigger insulin resistance and NASH (Cani et al. 2007, Tilg et al. 2016). To investigate the effect of S-PT84 on intestinal permeability in CL diet-induced NASH mice, we performed a fluorescence assay using carboxyfluorescein. Compared with NC mice, CL mice exhibited a threefold higher mean plasma CF level; S-PT84 significantly decreased plasma CF

levels (Fig. 4A). Similarly, although the CL diet increased LBP levels in plasma, S-PT84 treatment significantly decreased LBP levels (Fig. 4B). Furthermore, the CL diet decreased occludin, claudin-3, and claudin-7 expression in the colon and small intestine, the expression of which was rescued by S-PT84 administration (Fig. 4C). Compared with CL mice, CL+S-PT84 mice exhibited increased intestinal ZO-1 expression (Fig. 4C), corroborating the immunofluorescence findings.

Because LPS from enteric bacteria can activate Kupffer cells via the TLR4 and CD14 signaling pathways (Cani et al. 2007, Tilg et al. 2016), we investigated the correlation between the plasma LBP level and Kupffer cell activation. Importantly, the liver M1/M2 macrophage ratio was positively correlated with plasma LBP levels (Fig. 4D), indicating that S-PT84 reduces gut LPS leakage, alleviating the development of hepatic inflammation in NASH. 
A

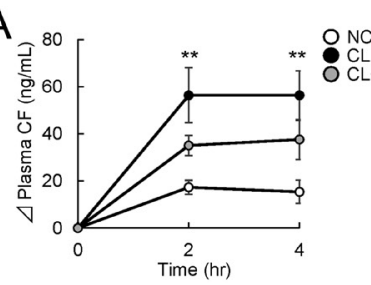

C

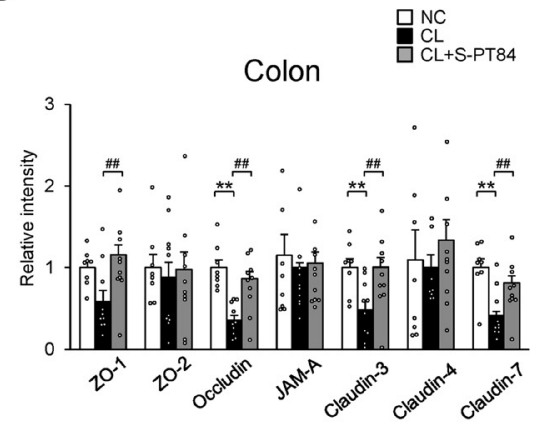

$\mathrm{B}$

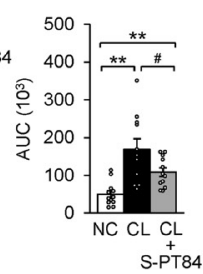

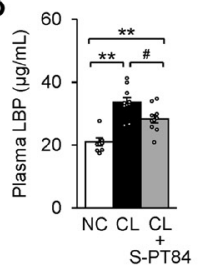
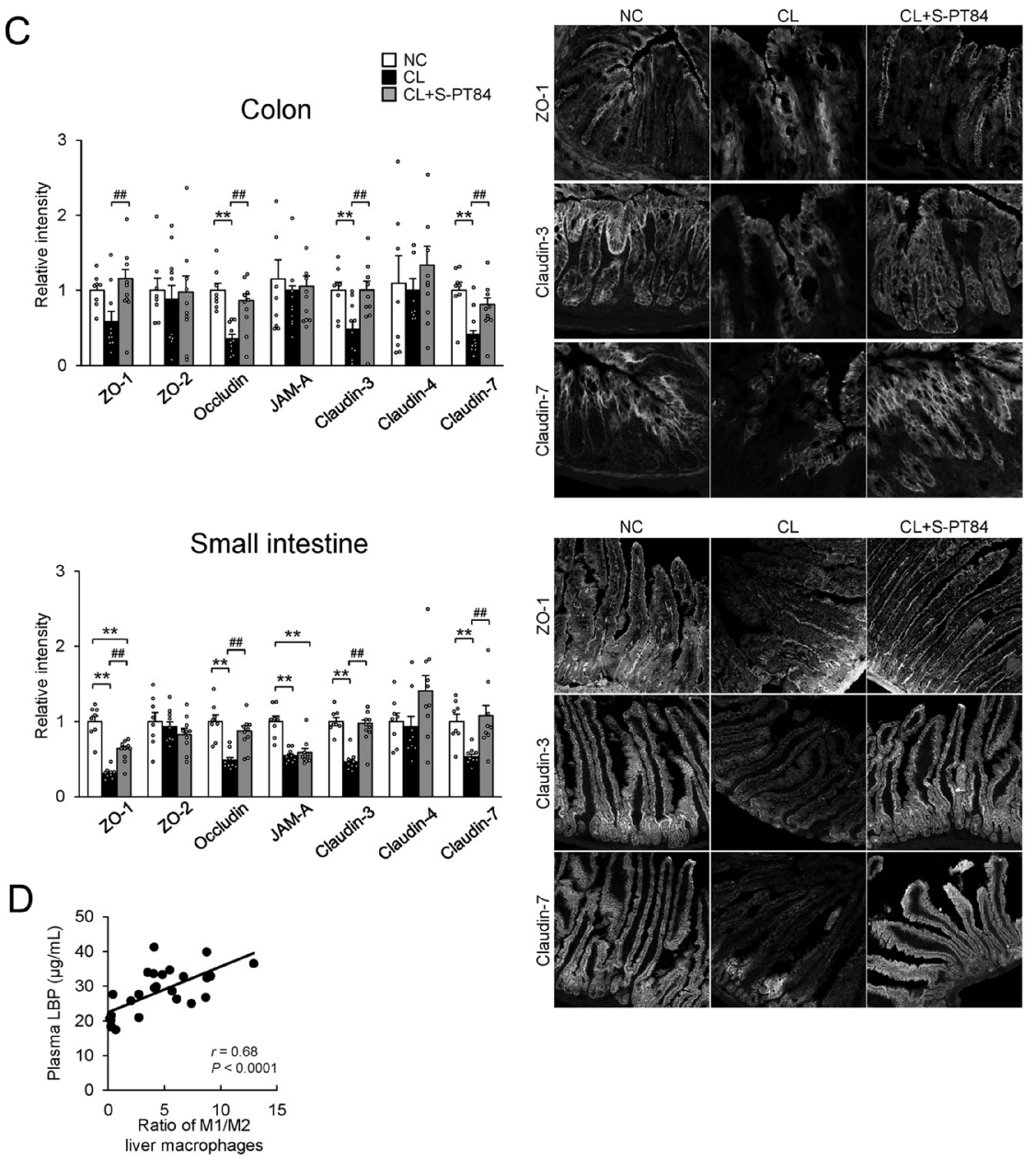

Figure 4

S-PT84 maintains intestinal epithelial barrier permeability. (A) Plasma CF oral challenge measured in mice fed NC or CL diet with or without S-PT84 ( $n=11-12)$. (B) Plasma lipopolysaccharide-binding protein (LBP) concentrations $(n=8-10)$. (C) Immunoblots and quantification of zonula occludens (ZO)-1, ZO-2, occludin, junctional adhesion molecule-A (JAM-A), claudin-3, claudin-4, and claudin-7 in the colon and small intestine $(n=8-10)$. (D) Correlations between the M1/M2 macrophage ratio and plasma LBP concentrations. Data are presented as mean \pm S.E.M. $* * P<0.01$ vs NC; $\# P<0.05$, $\# \#<0.01$ vs $C L$. NC, normal chow group; CL, high-cholesterol high-fat diet group; CL+S-PT84, CL with S-PT84 group.

\section{S-PT84 suppresses the intestinal accumulation of Th17 cells in NASH mice}

To examine the relevance of S-PT84 on the interplay between intestinal barrier function and gut immunity, we assessed the effects of S-PT84 on intestinal immune cell composition using flow cytometry. No significant changes in the total LP or M1/M2 macrophage populations were observed among $\mathrm{NC}, \mathrm{CL}$, and $\mathrm{CL}+\mathrm{S}-\mathrm{PT} 84$ mice (Supplementary Fig. 5A and B). Although CL diet significantly increased the numbers of $\mathrm{CD}^{+}, \mathrm{CD}^{+}$, and $\mathrm{CD}^{+} \mathrm{T}$ cells in the colon, S-PT84 did not affect the recruitment of these $\mathrm{T}$ cell populations (Fig. 5A). We next focused on Tregs and Th17 cells, which have been previously associated with intestinal barrier dysfunction (Blaschitz \& Raffatellu 2010, Lee et al. 2015, Tanoue et al. 2016). Compared with NC mice, CL mice had significantly more Tregs (Fig. 5B); nevertheless, S-PT84 did not affect the recruitment of Tregs (Fig. 5B). Conversely, CL mice had a higher number of Th17 cells than NC mice. Importantly, Th17 cell abundance decreased by $54 \%$ following administration of S-PT84 (Fig. 5B). These findings suggest that S-PT84 prevents Th17 cell accumulation in the intestinal LP of NASH mice. 
A

A

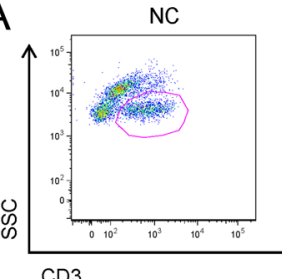

$C L$
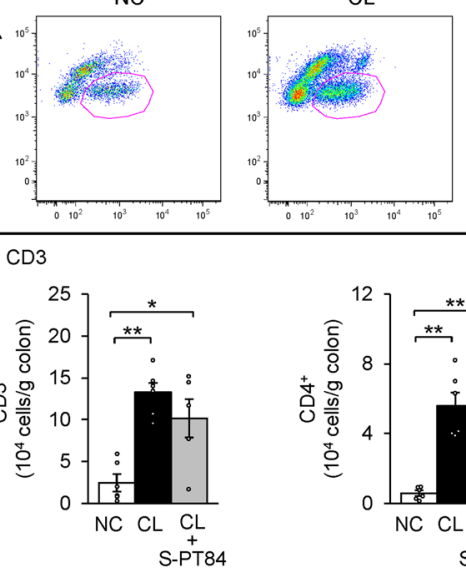
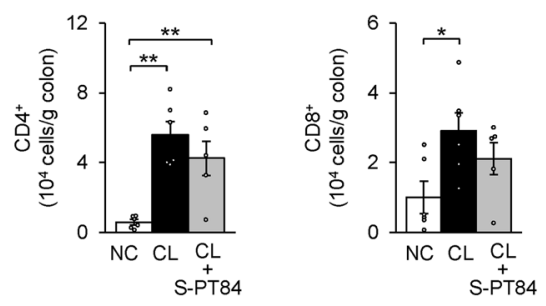

B
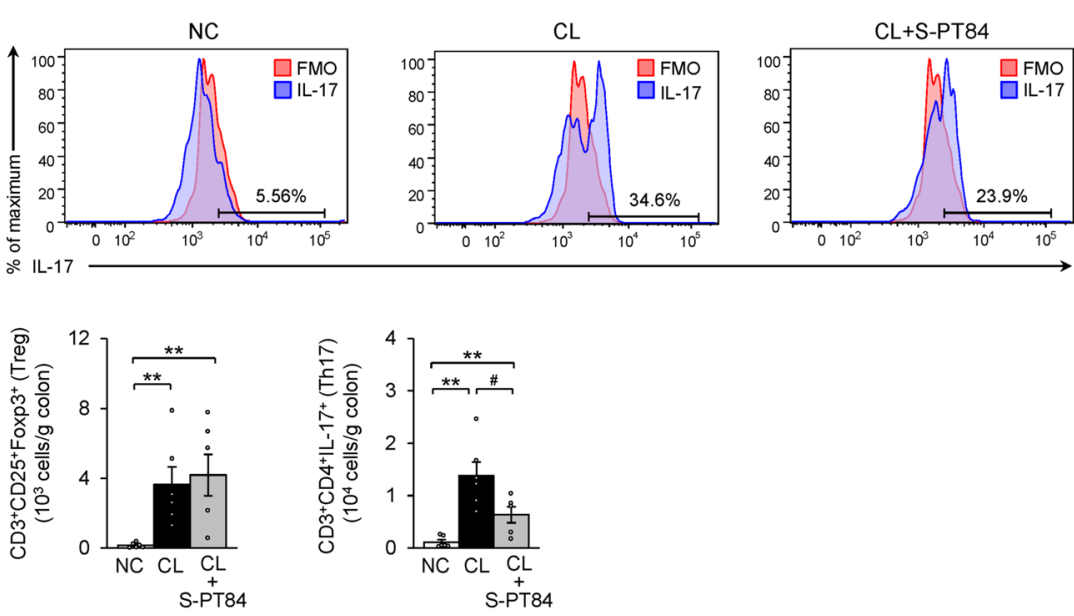

Figure 5

S-PT84 reduces interleukin (IL)-17-producing T (Th17) cells in the colon. (A) Quantification and representative histograms of $\mathrm{CD}^{+}, \mathrm{CD}^{+}$, and CD8 ${ }^{+} \mathrm{T}$ cells in the colons of mice $(n=5-6)$. (B) Quantification and representative histograms of regulatory T cells (Tregs) and Th17 cells in the colons of mice $(n=5-6)$. Data are presented as mean \pm S.E.M. $* P<0.05, \star \star P<0.01$ vs NC group: $\# P<0.05$ vs $C L$. NC, normal chow group; $C L$, high-cholesterol high-fat diet group; CL+S-PT84, CL with S-PT84 group.

\section{Discussion}

In this study, we demonstrated that S-PT84 alleviated hepatic fat accumulation, inflammation, fibrosis, and insulin resistance in a diet-induced NASH mouse model. Furthermore, S-PT84 inhibited the hepatic recruitment of monocytes and monocyte-derived macrophages, as well as promoted M2 macrophage polarization in the NASH liver. Notably, these beneficial effects of S-PT84 were associated with maintenance of the gut immune system and intestinal epithelial permeability (Fig. 6). To the best of our knowledge, this is the first report of the protective effects of S-PT84 against the development of NASH associated with metabolic endotoxemia.

The intestinal barrier plays a crucial role in the pathogenesis of NASH (Tilg et al. 2016). Intestinal barrier dysfunction increases the incorporation of LPS and other bowel contents into the portal vein, leading to hepatic inflammation and fibrosis via the LPS receptors TLR4 and CD14 (Fotbolcu \& Zorlu 2016, Tilg et al. 2016). In this study, we showed that the M1/M2 macrophage ratio in the liver was positively correlated with plasma LBP levels and hepatic Tlr4 and Cd14 mRNA levels, suggesting that metabolic endotoxemia is required for hepatic inflammation. Furthermore, CL diet increased intestinal permeability and reduced the levels of $\mathrm{TJ}$ proteins in the intestine. Indeed, increased intestinal permeability was associated with low ZO-1 expression in NASH patients (Miele et al. 2009). Although the mechanisms underlying hyperpermeability are unclear, Suzuki et al. reported that a high-fat diet itself rather than obesity increased intestinal permeability (Suzuki \& Hara 2010). These changes were also observed in the CL diet-induced NASH model, suggesting that CL and a high-fat diet can induce gut barrier disruption. Interestingly, S-PT84 significantly alleviated the increase in gut permeability associated with altered TJ protein expression, suggesting that protection of the gut barrier by S-PT84 leads to the suppression of hepatic inflammation and subsequent NASH development.

Mucosal immune cells are involved in intestinal barrier maintenance (Musch et al. 2002, Clayburgh et al. 2005). 


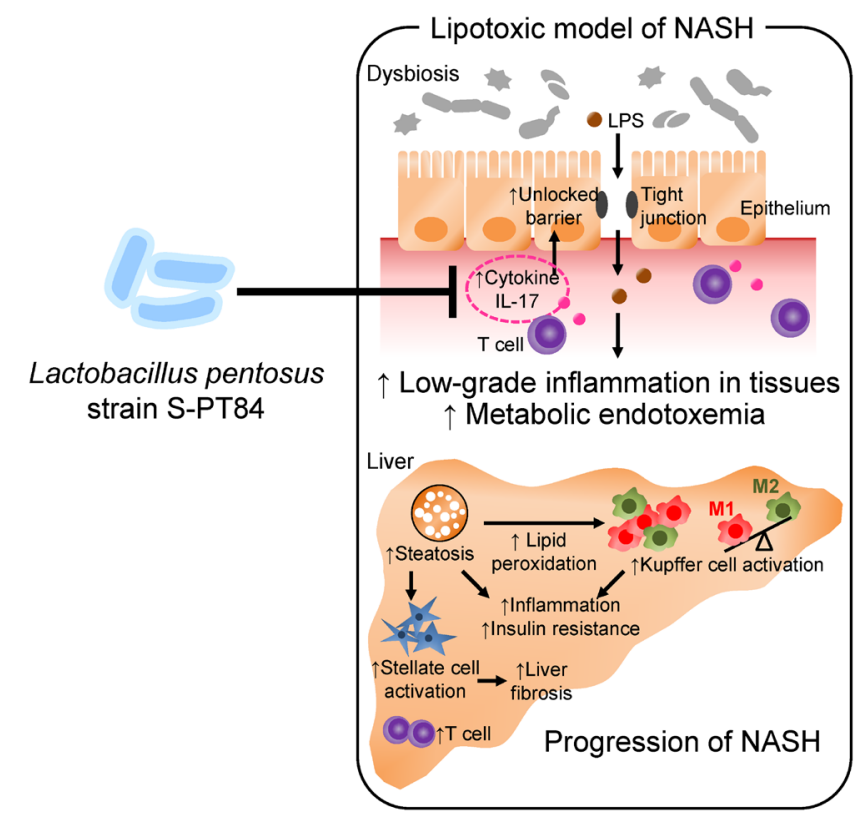

Figure 6

Schematic representation of the beneficial effects of S-PT84 on NASH progression by reducing intestinal permeability. In our lipotoxic NASH model, high-cholesterol high-fat diet induces tight junction dysfunction and enhances intestinal epithelial permeability via activation of IL-17 producing T cells. Increased intestinal permeability or 'leaky gut' results in metabolic endotoxemia followed by low-grade inflammation in the liver. Activated or M1-polarised macrophage/Kupffer cells and hepatic stellate cells induce insulin resistance, inflammation, and fibrosis in the fatty liver. The Lactobacillus pentosus strain S-PT84 inhibits the recruitment of IL-17-producing T cells and preserves gut barrier function. These beneficial effects of S-PT84 in the gut promote M2 polarisation in hepatic macrophages/Kupffer cells, thereby attenuating insulin resistance and NASH progression.

For example, 5-aminosalicylic acid, a gut antiinflammatory agent, improves intestinal inflammation and gut permeability, which is likely mediated by the mucosal immune system in mice with high-fat dietinduced obesity (Luck et al. 2015). In this study, we found a significant increase in the number of IL-17-producing $\mathrm{T}$ cells in the colon. The Th17 response prevents bacterial translocation by inducing the production of antimicrobial peptides (Blaschitz \& Raffatellu 2010, Lee et al. 2015). However, intestinal IL-17 promoted TJ structure alterations and bacterial dissemination in sepsis models (Meng et al. 2015). Moreover, intestinal IL-17 levels were elevated in mice with steatohepatitis, and increased numbers of Th17 cells were observed among the peripheral blood mononuclear cells of NASH patients (Rau et al. 2016, Zhou et al. 2017). In our mouse model, Th17 cells may drive changes in the integrity of the intestinal epithelium. We demonstrated that S-PT84 suppressed the increase in the numbers of Th17 cells in the LP. Similarly, a lactic acid bacterium reportedly suppressed the secretion of Th17 cell-associated cytokines (Chen et al. 2015). Pro-inflammatory cytokines increased epithelial permeability by decreasing TJ protein expression (Suzuki 2013). Thus, S-PT84 may attenuate pro-inflammatory cytokine release from Th17 cells to maintain TJ structure.

Ectopic fat in the liver has also been implicated in the development of insulin resistance and NASH (Matsuzawa et al. 2007, Ota et al. 2007, Diehl \& Day 2017). Hepatic lipotoxicity induces oxidative stress, leading to inflammation and fibrosis mediated by activated Kupffer cells and HSCs (Matsuzawa et al. 2007, Ota et al. 2007). S-PT84 reduced hepatic and epididymal fat accumulation, which is associated with decreased oxidative stress. S-PT84 also delayed triacylglycerol absorption, likely by inhibiting pancreatic lipase (Zhou et al. 2013). Therefore, S-PT84 appears to suppress ectopic fat accumulation by delaying intestinal fat absorption. Prolonged LPS administration mimics metabolic endotoxemia-induced obesity, ectopic fat accumulation, and liver insulin resistance (Cani et al. 2007). In this study, S-PT84 decreased intestinal hyperpermeability in CL diet-fed mice, suggesting that S-PT84 improves aberrant lipid accumulation at least partly by maintaining the gut barrier function. It is also possible that S-PT84 attenuates hepatic steatosis and insulin resistance by enhancing insulin signaling in adipose tissue and subsequently reducing adipose tissue weight.

The innate immune system in the liver is responsible for the development of NASH (Li et al. 2005, Kremer et al. 2010). Supplementation of S-PT84 did not rescue the decrease in the numbers of hepatic NKT cells. Given that S-PT84 stimulated the activity of NK and NKT cells in vitro (Koizumi et al. 2008), S-PT84 may not directly affect innate immune cells in the liver. Recent animal and human studies have investigated the relationship between gut microbiota and NASH progression (Arslan 2014, Paolella et al. 2014). We found that CL diet altered the microbiota profile, although S-PT84 did significantly restore these alterations (data not shown).

This study has several limitations. The precise molecular mechanisms of S-PT84 were not determined. We also did not provide direct evidence that S-PT84 suppresses the activity of colonic Th17 cells and hepatic macrophages, or fat absorption. The intestinal barrier consists of an external physical barrier and an inner functional immunological barrier (Bischoff et al. 2014). Because the factors contributing to changes in intestinal 
permeability triggered by a CL diet have not been fully elucidated, further work is needed to identify the cellular or molecular targets of S-PT84.

Despite these limitations, our results indicate that S-PT84 improves NASH and insulin resistance. Because S-PT84 is used as a supplement for immune modulation and obesity prevention, its application as a treatment for NASH is feasible. Clinical trials investigating the effects of S-PT84 in NASH patients are warranted.

In conclusion, we provide evidence that L. pentosus S-PT84 attenuates lipotoxicity-induced hepatic insulin resistance and inflammation in NASH by maintaining the gut barrier and intestinal permeability, as well as suppressing metabolic endotoxemia via activation of Th17 cells. Moreover, S-PT84 exerts anti-inflammatory effects in the NASH liver by modulating the M1/M2 macrophage ratio (Fig. 6). Therefore, S-PT84 is a promising and safe approach to prevent the development of NASH.

\section{Supplementary materials}

This is linked to the online version of the paper at https://doi.org/10.1530/ JOE-20-0105.

\section{Declaration of interest}

The authors declare that there is no conflict of interest that could be perceived as prejudicing the impartiality of the research reported.

\section{Funding}

This work was supported by a Grant-in-Aid for Scientific Research (C) from MEXT, Japan (grant number 19K11764).

\section{Acknowledgements}

The authors thank M Nakayama and K Hara (Kanazawa University, Japan) for technical assistance and animal care.

\section{References}

Arslan N 2014 Obesity, fatty liver disease and intestinal microbiota. World Journal of Gastroenterology 20 16452-16463. (https://doi.org/10.3748/ wjg.v20.i44.16452)

Bischoff SC, Barbara G, Buurman W, Ockhuizen T, Schulzke JD, Serino M, Tilg H, Watson A \& Wells JM 2014 Intestinal permeability - a new target for disease prevention and therapy. BMC Gastroenterology 14 189. (https://doi.org/10.1186/s12876-014-0189-7)

Blaschitz C \& Raffatellu M 2010 Th17 cytokines and the gut mucosal barrier. Journal of Clinical Immunology 30 196-203. (https://doi. org/10.1007/s10875-010-9368-7)

Cani PD, Amar J, Iglesias MA, Poggi M, Knauf C, Bastelica D, Neyrinck AM, Fava F, Tuohy KM, Chabo C, et al. 2007 Metabolic endotoxemia initiates obesity and insulin resistance. Diabetes $\mathbf{5 6}$ 1761-1772. (https://doi.org/10.2337/db06-1491)
Chen L, Zou Y, Peng J, Lu F, Yin Y, Li F \& Yang J 2015 Lactobacillus acidophilus suppresses colitis-associated activation of the IL-23/ Th17 axis. Journal of Immunology Research 2015 909514. (https://doi. org/10.1155/2015/909514)

Clayburgh DR, Barrett TA, Tang Y, Meddings JB, Van Eldik LJ, Watterson DM, Clarke LL, Mrsny RJ \& Turner JR 2005 Epithelial myosin light chain kinase-dependent barrier dysfunction mediates $\mathrm{T}$ cell activation-induced diarrhea in vivo. Journal of Clinical Investigation 115 2702-2715. (https://doi.org/10.1172/JCI24970)

Denning TL, Wang YC, Patel SR, Williams IR \& Pulendran B 2007 Lamina propria macrophages and dendritic cells differentially induce regulatory and interleukin 17-producing T cell responses. Nature Immunology 8 1086-1094. (https://doi.org/10.1038/ni1511)

Diehl AM \& Day C 2017 Cause, pathogenesis, and treatment of nonalcoholic steatohepatitis. New England Journal of Medicine 377 2063-2072. (https://doi.org/10.1056/NEJMra1503519)

Fotbolcu H \& Zorlu E 2016 Nonalcoholic fatty liver disease as a multisystemic disease. World Journal of Gastroenterology 22 4079-4090. (https://doi.org/10.3748/wjg.v22.i16.4079)

Friedman SL, Neuschwander-Tetri BA, Rinella M \& Sanyal AJ 2018 Mechanisms of NAFLD development and therapeutic strategies. Nature Medicine 24 908-922. (https://doi.org/10.1038/s41591-0180104-9)

Gonzalez-Mariscal L, Betanzos A, Nava P \& Jaramillo BE 2003 Tight junction proteins. Progress in Biophysics and Molecular Biology 81 1-44. (https://doi.org/10.1016/s0079-6107(02)00037-8)

Groschwitz KR \& Hogan SP 2009 Intestinal barrier function: molecular regulation and disease pathogenesis. Journal of Allergy and Clinical Immunology 124 3-20; quiz 21-22. (https://doi.org/10.1016/j. jaci.2009.05.038)

Izumo T, Izumi F, Nakagawa I, Kitagawa Y, Shibata H \& Kiso Y $2011 a$ Influence of Lactobacillus pentosus S-PT84 ingestion on the mucosal immunity of healthy and Salmonella Typhimurium-infected mice. Biosci Microflora 30 27-35. (https://doi.org/10.12938/bifidus.30.27)

Izumo T, Ida M, Maekawa T, Furukawa Y, Kitagawa Y \& Kiso Y $2011 b$ Comparison of the immunomodulatory effects of live and heat-killed Lactobacillus pentosus. Journal of Health Science 57 304-310. (https:// doi.org/10.1248/jhs.57.304)

Izumo T, Maekawa T, Ida M, Kishi A, Akatani K, Kitagawa Y \& Kiso Y 2011c Effect of Lactobacillus pentosus S-PT84 ingestion on IFN-alpha production from plasmacytoid dendritic cells by virus stimulation. Bioscience, Biotechnology, and Biochemistry 75 370-372. (https://doi. org/10.1271/bbb.100696)

Kazankov K, Jorgensen SMD, Thomsen KL, Moller HJ, Vilstrup H, George J, Schuppan D \& Gronbaek H 2019 The role of macrophages in nonalcoholic fatty liver disease and nonalcoholic steatohepatitis. Nature Reviews: Gastroenterology and Hepatology 16 145-159. (https:// doi.org/10.1038/s41575-018-0082-x)

Kitade H, Sawamoto K, Nagashimada M, Inoue H, Yamamoto Y, Sai Y, Takamura T, Yamamoto H, Miyamoto K, Ginsberg HN, et al. 2012 CCR5 plays a critical role in obesity-induced adipose tissue inflammation and insulin resistance by regulating both macrophage recruitment and M1/M2 status. Diabetes 61 1680-1690. (https://doi. org/10.2337/db11-1506)

Koizumi S, Wakita D, Sato T, Mitamura R, Izumo T, Shibata H, Kiso Y, Chamoto K, Togashi Y, Kitamura H, et al. 2008 Essential role of toll-like receptors for dendritic cell and NK1.1(+) cell-dependent activation of type 1 immunity by Lactobacillus pentosus strain S-PT84. Immunology Letters 120 14-19. (https://doi.org/10.1016/j.imlet.2008.06.003)

Kremer M, Thomas E, Milton RJ, Perry AW, van Rooijen N, Wheeler MD, Zacks S, Fried M, Rippe RA \& Hines IN 2010 Kupffer cell and interleukin-12-dependent loss of natural killer T cells in hepatosteatosis. Hepatology 51 130-141. (https://doi.org/10.1002/ hep. 23292)

Lee JS, Tato CM, Joyce-Shaikh B, Gulen MF, Cayatte C, Chen Y, Blumenschein WM, Judo M, Ayanoglu G, McClanahan TK, et al. 
2015 Interleukin-23-independent IL-17 production regulates intestinal epithelial permeability. Immunity 43 727-738. (https://doi. org/10.1016/j.immuni.2015.09.003)

Li Z, Soloski MJ \& Diehl AM 2005 Dietary factors alter hepatic innate immune system in mice with nonalcoholic fatty liver disease. Hepatology 42 880-885. (https://doi.org/10.1002/hep.20826)

Luck H, Tsai S, Chung J, Clemente-Casares X, Ghazarian M, Revelo XS, Lei H, Luk CT, Shi SY, Surendra A, et al. 2015 Regulation of obesityrelated insulin resistance with gut anti-inflammatory agents. Cell Metabolism 21 527-542. (https://doi.org/10.1016/j.cmet.2015.03.001)

Ma X, Hua J \& Li Z 2008 Probiotics improve high fat diet-induced hepatic steatosis and insulin resistance by increasing hepatic NKT cells. Journal of Hepatology 49 821-830. (https://doi.org/10.1016/j. jhep.2008.05.025)

Mantovani A, Sica A, Sozzani S, Allavena P, Vecchi A \& Locati M 2004 The chemokine system in diverse forms of macrophage activation and polarization. Trends in Immunology 25 677-686. (https://doi. org/10.1016/j.it.2004.09.015)

Matsuzawa N, Takamura T, Kurita S, Misu H, Ota T, Ando H, Yokoyama M, Honda M, Zen Y, Nakanuma Y, et al. 2007 Lipid-induced oxidative stress causes steatohepatitis in mice fed an atherogenic diet. Hepatology 46 1392-1403. (https://doi.org/10.1002/hep.21874)

Meng J, Banerjee S, Li D, Sindberg GM, Wang F, Ma J \& Roy S 2015 Opioid exacerbation of gram-positive sepsis, induced by gut microbial modulation, is rescued by IL-17A neutralization. Scientific Reports $\mathbf{5}$ 10918. (https://doi.org/10.1038/srep10918)

Miele L, Valenza V, La Torre G, Montalto M, Cammarota G, Ricci R, Masciana R, Forgione A, Gabrieli ML, Perotti G, et al. 2009 Increased intestinal permeability and tight junction alterations in nonalcoholic fatty liver disease. Hepatology 49 1877-1887. (https://doi.org/10.1002/ hep.22848)

Musch MW, Clarke LL, Mamah D, Gawenis LR, Zhang Z, Ellsworth W, Shalowitz D, Mittal N, Efthimiou P, Alnadjim Z, et al. 2002 T cell activation causes diarrhea by increasing intestinal permeability and inhibiting epithelial $\mathrm{Na}+/ \mathrm{K}+-\mathrm{ATPa} e$. Journal of Clinical Investigation 110 1739-1747. (https://doi.org/10.1172/JCI0215695)

Ni Y, Nagashimada M, Zhan L, Nagata N, Kobori M, Sugiura M, Ogawa K, Kaneko S \& Ota T 2015 Prevention and reversal of lipotoxicityinduced hepatic insulin resistance and steatohepatitis in mice by an antioxidant carotenoid, beta-cryptoxanthin. Endocrinology 156 987-999. (https://doi.org/10.1210/en.2014-1776)

Ni Y, Zhuge F, Nagashimada M, Nagata N, Xu L, Yamamoto S, Fuke N, Ushida Y, Suganuma H, Kaneko S, et al. 2020 Lycopene prevents the progression of lipotoxicity-induced nonalcoholic steatohepatitis by decreasing oxidative stress in mice. Free Radical Biology and Medicine 152 571-582. (https://doi.org/10.1016/j.freeradbiomed.2019.11.036)

Nonaka Y, Izumo T, Izumi F, Maekawa T, Shibata H, Nakano A, Kishi A, Akatani K \& Kiso Y 2008 Antiallergic effects of Lactobacillus pentosus strain S-PT84 mediated by modulation of Th1/Th2 immunobalance and induction of IL-10 production. International Archives of Allergy and Immunology 145 249-257. (https://doi.org/10.1159/000109294)
Ota T, Takamura T, Kurita S, Matsuzawa N, Kita Y, Uno M, Akahori H, Misu H, Sakurai M, Zen Y, et al. 2007 Insulin resistance accelerates a dietary rat model of nonalcoholic steatohepatitis. Gastroenterology 132 282-293. (https://doi.org/10.1053/j.gastro.2006.10.014)

Paolella G, Mandato C, Pierri L, Poeta M, Di Stasi M \& Vajro P 2014 Gut-liver axis and probiotics: their role in non-alcoholic fatty liver disease. World Journal of Gastroenterology 20 15518-15531. (https:// doi.org/10.3748/wjg.v20.i42.15518)

Rau M, Schilling AK, Meertens J, Hering I, Weiss J, Jurowich C, Kudlich T, Hermanns HM, Bantel H, Beyersdorf N, et al. 2016 Progression from nonalcoholic fatty liver to nonalcoholic steatohepatitis is marked by a higher frequency of Th17 cells in the liver and an increased Th17/resting regulatory $\mathrm{T}$ cell ratio in peripheral blood and in the liver. Journal of Immunology 196 97-105. (https://doi.org/10.4049/ jimmunol.1501175)

Suzuki T 2013 Regulation of intestinal epithelial permeability by tight junctions. Cellular and Molecular Life Sciences 70 631-659. (https://doi. org/10.1007/s00018-012-1070-x)

Suzuki T \& Hara H 2010 Dietary fat and bile juice, but not obesity, are responsible for the increase in small intestinal permeability induced through the suppression of tight junction protein expression in LETO and OLETF rats. Nutrition and Metabolism 7 19. (https://doi. org/10.1186/1743-7075-7-19)

Tanoue T, Atarashi K \& Honda K 2016 Development and maintenance of intestinal regulatory T cells. Nature Reviews: Immunology 16 295-309. (https://doi.org/10.1038/nri.2016.36)

Tilg H \& Moschen AR 2010 Evolution of inflammation in nonalcoholic fatty liver disease: the multiple parallel hits hypothesis. Hepatology $\mathbf{5 2}$ 1836-1846. (https://doi.org/10.1002/hep.24001)

Tilg H, Cani PD \& Mayer EA 2016 Gut microbiome and liver diseases. Gut 65 2035-2044. (https://doi.org/10.1136/gutjnl-2016-312729)

Zeng Y, Zhang H, Zong L, Tsao R, Arie H, Izumo T, Shibata H \& Mine Y 2019 Lactobacillus pentosus S-PT84 prevents LPS-induced low-grade chronic inflammation in a C57BL/6J mouse model. Journal of Functional Foods 62 103526. (https://doi.org/10.1016/j. jff.2019.103526)

Zhou Y, Inoue N, Ozawa R, Maekawa T, Izumo T, Kitagawa Y, Kiso Y, Shibata H \& Ikeda I 2013 Effects of heat-killed Lactobacillus pentosus S-PT84 on postprandial hypertriacylglycerolemia in rats. Bioscience, Biotechnology, and Biochemistry 77 591-594. (https://doi.org/10.1271/ bbb.120830)

Zhou D, Pan Q, Liu XL, Yang RX, Chen YW, Liu C \& Fan JG 2017 Clostridium butyricum B1 alleviates high-fat diet-induced steatohepatitis in mice via enterohepatic immunoregulation. Journal of Gastroenterology and Hepatology 32 1640-1648. (https://doi. org/10.1111/jgh.13742)

Zhuge F, Ni Y, Nagashimada M, Nagata N, Xu L, Mukaida N, Kaneko S \& Ota T 2016 DPP-4 inhibition by linagliptin attenuates obesityrelated inflammation and insulin resistance by regulating M1/ M2 macrophage polarization. Diabetes 65 2966-2979. (https://doi. org/10.2337/db16-0317)

Received in final form 29 July 2020

Accepted 26 August 2020

Accepted Manuscript published online 27 August 2020 https://joe.bioscientifica.com https://doi.org/10.1530/JOE-20-0105
(C) 2020 Society for Endocrinology Published by Bioscientifica Ltd. Printed in Great Britain 